\title{
Concursos educacionais: experiências exitosas de projetos pedagógicos desenvolvidos no laboratório de informática da escola.
}

\author{
Tereza Cristina Dourado Carrah Vieira Carvalho
}

Especialista em Informática Educativa - Falc - Faculdade da Aldeia de Carapicuíba Maracanaú-Ceará

tiaterezadourado@gmail.com

\begin{abstract}
This article is the result of a case study with students from Elementary School I, carried out in a public school in the city of MaracanauCeará, about two successful experiences of pedagogical projects carried out in the computer lab motivated by educational competitions. In both experiences, students, such as the school and teacher, were awarded prizes and / or certifications, including the Teachers of Brazil Award at the state level held by the Ministry of Education (MEC) in2017. The study through projects motivated by educational contests provided stimulus in the students, because it brought autonomy, mobilization, motivation, creativity, learning and awareness, among other aspects.
\end{abstract}

Resumo. Este artigo resulta de um estudo de caso com alunos do Ensino Fundamental I, realizado em uma escola pública do Município de Maracanaú-Ceará, acerca de duas experiências exitosas de projetos pedagógicos realizados no laboratório de informática motivadas por concursos educacionais. Nas duas experiências tantos alunos, como a escola e professor foram agraciados com prêmios elou certificações, incluindo o Prêmio Professores do Brasil na etapa estadual realizado pelo Ministério da Educação (MEC) em2017. O estudo por meio de projetos motivados por concursos educacionais proporcionou estímulo nos alunos, pois trouxe autonomia, mobilização, motivação, criatividade, aprendizado $e$ sensibilização, dentre outros aspectos.

\section{Introdução}

As novas relações entre tecnologias de informação e comunicação e a sociedade vêm transformando o nosso dia a dia. E o setor educacional tem compreendido essas mudanças, merecendo destaque por possuir diversos aparatos tecnológicos comumente encontrados no ambiente escolar, criando, assim, a necessidade de maior adaptação das práticas pedagógicas à incorporação dessas tecnologias ao ensino-aprendizagem, principalmente porque o aluno de hoje faz parte de uma geração cada vez mais conectada [Gabriel 2013].

Diante disso, se faz necessário que professores renovem suas práticas, aproveitando-se desses novos aparatos tecnológicos, para o uso consciente dessas ferramentas, dentro e fora da escola. E a pedagogia de projeto pode ser um bom caminho para essa renovação. A ideia de projeto é própria da atividade humana, da sua 
VII Congresso Brasileiro de Informática na Educação (CBIE 2018)

Anais do XXIV Workshop de Informática na Escola (WIE 2018)

forma de pensar em algo que deseja tornar real, portanto, o projeto é inseparável do sentido da ação [Almeida 2002].

Podemos citar a produção de vídeos e a utilização da música por meio de tecnologias digitais como recursos pedagógicos que podem ser utilizado no ensinoaprendizagem e na criação de projetos pedagógicos educativos.

Vale ressaltar, que no desenvolvimento de projetos, a mediação do professor é fundamental, pois ao mesmo tempo em que o aluno precisa reconhecer a sua própria autoria no projeto, ele também precisa sentir a presença do professor que ouve, questiona e orienta, visando propiciar a construção de conhecimento do aluno.

Sobre a utilização de vídeos na escola, Caetano \& Falkembach (2013) ensinam que dependendo de como o vídeo foi planejado e produzido, ele pode ser, por si, um objeto de aprendizagem. O vídeo, além de ser um recurso pedagógico poderoso, por envolver os vários sentidos da percepção humana, possui características não vistas isoladamente, mas interligadas. Sobre isso, Moran (1995) explica que o vídeo é sensorial, visual, com linguagens falada, musical e escrita; linguagens que interagem superpostas, interligadas, somadas, não separadas.

Referindo-se a utilização da música por meio de tecnologias digitais, entendemos que de acordo com Acampora (2014) os benefícios da música na educação aumentam a inteligência auditiva e ajuda no desenvolvimento integral da criança. No setor neurológico, os estímulos musicais também podem facilitar o desenvolvimento linguístico e motor.

Em comum, estes dois recursos pedagógicos tem como propósito a busca pela equidade na educação, o protagonismo dos alunos, a formação de uma visão crítica de sociedade e a importância de despertar nos alunos o espírito curioso e a paixão por aprender. Neste sentido, elas podem contribuir com o desafio de formar cidadãos preparados para viver em sociedade, que assumam posturas ativas mediante as circunstâncias de um mundo globalizado e competitivo, e que consigam adaptar-se às rápidas mudanças econômicas, colaborando na construção de uma sociedade em que os indivíduos estejam preparados para empreender e inovar com propósito.

Neste sentido, esta pesquisa tem como objetivo geral: demonstrar duas experiências exitosas de projetos realizados no laboratório de informática de uma escola do municipal do município de Mararacanaú- Ceará, motivadas por concursos educacionais. Como objetivos específicos: 1) relatar experiência de um projeto que envolveu a produção, criação e compartilhamento de vídeos no Youtube motivados por um concurso educacional digital, realizado pela entidade Seja Digital sobre o fim do sinal analógico de televisão e 2) narrar uma prática de um projeto que tornou-se permanente dentro da escola, onde envolve a música por meio de tecnologias móveis e que conquistou prêmios em concursos dentro do município e o Prêmio Professores do Brasil do MEC na etapa estadual.

Diante dos objetivos acima apresentados, o ponto a ser considerado: Como projetos educativos, motivados por concursos educacionais podem levar o aluno a produzir, levantar dúvidas, pesquisar e criar relações, que incentivam novas buscas, descobertas, compreensões e reconstruções do conhecimento? Na sequência, detalharemos o desenvolvimento do trabalho. 
VII Congresso Brasileiro de Informática na Educação (CBIE 2018)

Anais do XXIV Workshop de Informática na Escola (WIE 2018)

\section{Metodologia}

O método utilizado na pesquisa é o científico e indutivo. Como ensina Ruiz (2010), a indução é um processo inverso da dedução, ela caminha do registro de fatos menos gerais para chegar a conclusão desdobrada ou ampliada em enunciado mais geral. Mediante a experiência que o projeto tem a intenção estabelecer, tendo como estudo uma escola pública, do Município de Maracanaú - Ceará, é que muitas outras escolas em todo Estado, ou até mesmo em todo o País, poderão se espelhar e ter como modelo.

A pesquisa se classifica como descritiva e tem como instrumento um estudo de caso com alunos do Ensino Fundamental I, da Escola Pública Municipal de Ensino Infantil e Ensino Fundamental PFFS. O estudo de caso é um método qualitativo que consiste, geralmente, em uma maneira de aprofundar uma unidade individual. Tal instrumento de busca serve para responder a questionamentos do pesquisador, o qual não tem muito controle sobre o fenômeno estudado. Na lição de Robert Yin (2001), o estudo de caso é uma estratégia de pesquisa que compreende um método abrangendo abordagens especificas de coletas e análise de dados.

Nesse sentido, ao mesmo tempo em que a pesquisa é realizada e analisada, ela propõe um aprimoramento de suas práticas correlacionadas ao uso de recursos pedagógicos digitais por meio de concursos educacionais e os resultados de tal ação dentro e fora da escola.

\subsection{Local e participantes}

A experiência descrita no artigo foram desenvolvidas no Laboratório de Informática Educativa (LIE) da escola. De porte pequeno, a escola possui no total de 340 alunos matriculados nos turno da manhã e da tarde, sendo 100 alunos da Educação Infantil e 240 estudantes do Ensino Fundamental I.

Por meio de conversas informais, constatamos que a escola, apesar de ser localizada na periferia de Maracanaú- Ceará, tendo em na sua maioria alunos de baixa renda, boa parte dos pais destes possuíam smarthones e acessos às redes sociais.

Os procedimentos metodológicos adotados para a pesquisa foram realizados nos meses de fevereiro a novembro de 2017 , com os alunos do $2^{\circ}$ ao $5^{\circ}$ ano do Ensino Fundamental I, com idade media de 7 a 11 anos. Os projetos desenvolvidos foram coordenados pela professora do LIE e conta com a participação direta dos discentes e indireta do corpo docente, núcleo gestor e comunidade. Todos os sujeitos participaram no suporte e apoio aos projetos.

\subsection{Materiais e métodos}

Para o desenvolvimento dos projetos, foram utilizados como instrumentos principais: computadores, laptops Xo, tablets, smarthones, cabos p2, lousa digital, câmara de aparelhos celulares e de vídeo, editor de vídeos, caixas de som, amplificadores e dentre outros.

Quanto à ação pedagógica, detalharemos nessa pesquisa, conforme 0 desenvolvimento de cada projeto dentro da escola: 
VII Congresso Brasileiro de Informática na Educação (CBIE 2018)

Anais do XXIV Workshop de Informática na Escola (WIE 2018)

\subsubsection{Projeto Youtuber: Seja Digital e não deixe ninguém para trás}

O projeto foi desenvolvido no âmbito do concurso educacional Aluno Digital, por meio da criação, produção e compartilhamento de vídeos tutoriais no Youtube com objetivo de sensibilizar a população sobre o fim do sinal analógico de televisão. A entidade Seja Digital foi responsável pela operacionalização do concurso educacional digital, proporcionando aos vencedores prêmios como Tvs, tablets e Kits conversores.

Para participar do concurso, os alunos deveriam criar vídeos até 120 segundos e postar em uma rede social que gerasse um link, cujo tema era "Seja Digital e não deixe ninguém para trás". O Youtube foi o site escolhido para divulgação dos vídeos. Como lecionam Burgess e Green (2009), embora o YouTube não seja o único site de compartilhamento de vídeos da internet, sua rápida ascensão e a ampla variedade de conteúdo o tornam bastante útil para o entendimento das relações ainda em evolução entre as novas tecnologias de mídia, as indústrias criativas e as políticas da cultura popular.

O concurso foi dividido em três categorias: 1) Seja um Youtuber: estudantes do $1^{\mathrm{o}}$ ao $4^{\mathrm{o}}$ ano do ensino fundamental I; 2) Você é um repórter: alunos do $5^{\mathrm{o}}$ ao $7^{\mathrm{o}}$ ano do Ensino Fundamental e 3) Você é o jornalista: os do $8^{\circ}$ e $9^{\circ}$ ano do Ensino Fundamental. As três categorias visavam a estimular autonomia dos alunos por meio da produção de vídeos.

A ação pedagógica nesse projeto foi assim dividida: no primeiro momento, os alunos foram encaminhados ao laboratório de informática e apresentados ao site YouTube, no qual se apropriaram da ferramenta, sendo conscientizados quanto à utilização adequada e inadequada. A ação seguinte foi apresentar e motivar os alunos a participarem do concurso educacional, com explicações sobre regras e as funcionalidades contidas no regulamento. A ideia foi utilizar o concurso como motivação para um aprendizado prazeroso, dinâmico e criativo dessa ferramenta. Durante uma semana, foram abordados e discutidos com as turmas do $2^{\circ}$ ao $5^{\circ}$ ano do Ensino Fundamental I da escola sobre os assuntos pertinentes ao concurso e modalidades de produção e compartilhamento de vídeos.

Os alunos realizaram pesquisas por meio da internet para compreender melhor o assunto abordado e planejaram roteiros completos para a criação dos vídeos. Willoughby (2017) ensina que é importante planejar o que vai dizer, mesmo que esteja fazendo um tutorial. $\mathrm{O}$ autor comenta ainda, que adora escrever roteiros porque é o momento que o vídeo começa a ganhar vida.

Já nas semanas seguintes, foram realizadas as produções, edições dos vídeos e inscrições dos alunos no site para efetivar a participação no concurso. Nas aulas posteriores, mostramos às turmas o resultado dos vídeos produzidos pelos alunos e professor. Segundo Veen e Vrakking (2009), a escola é como um espaço que se apropria das tecnologias e evolui para que essas estejam a serviço da emancipação da pessoa como sujeito autônomo, que se permite experimentar o novo a todo instante.

Para edição dos vídeos, foi utilizada a ferramenta Movie Maker, o editor de vídeo do Windows. Para Willoughby (2017) a edição é a cereja do bolo, o autor ressalta que, quando você edita, consegue ver seu filme completo, com os efeitos que melhoram a visualização. 
VII Congresso Brasileiro de Informática na Educação (CBIE 2018)

Anais do XXIV Workshop de Informática na Escola (WIE 2018)

\subsubsection{Projeto Música e Tecnologia na escola}

Diante das possibilidades tecnológicas atuais e apoiadas na lei $\mathrm{n}^{\mathrm{o}} 11.769$ de 18 de agosto de 2008, que preconiza a música como conteúdo obrigatório, foi criado o projeto intitulado "Projeto Música e Tecnologia na Escola", o qual objetivava promover a educação musical neste novo ambiente de prática educacional mediado pela presença das tecnologias móveis apoiados pelos softwares de abordagem construtivista disponível nos laptops. Ou seja, promover o estudo da música de forma interdisciplinar associado à tecnologia.

O projeto teve ínicio em agosto de 2015 e continua como projeto permanente dentro da escola. A Escola foi uma das contempladas com a doação dos laptops, advindos do projeto UCA (Um Computador por Aluno). Logo após uma das primeiras oficinas ministradas pelo Núcleo de Tecnologia Educacional de Maracanaú (NUTEM) acerca das possibilidades de uso pedagógico dos programas disponíveis no sistema operacional Linux Suggar de abordagem progressista pouco conhecido no país, vislumbrou-se a ideia de inserir o laptop nas atividades curriculares da escola. Além dos laptops foram inseridos no projeto tablets e notebooks.

Para o ensino de música, nos laptops o software utilizado é o Tam Tam Mini, nos tablets o Perfect Piano e nos notebooks o Little Piano. Todos são programas que possibilita a compilação de instrumentos musicais por meio da criação de sons, melodias e músicas, capazes de proporcionar que os alunos experimentem, explorem e criem suas próprias melodias.

O objetivo principal do projeto era fazer com que os alunos tocassem músicas usando ferramentas tecnógicas. Mas para isso era necessário conhecer o alfabeto e a localização das letras no teclado, pois cada letra é correspondente a uma nota musical. Nesse sentido, quanto à ação pedagógica, nos encontros iniciais do projeto foi abordado fundamentos de teoria musical, apresentado as semelhanças e diferenças da tecnologia do laptop, tablet e notebook com o teclado musical. Em seguida, iniciou-se o treinamento da habilidade dos alunos ao dedilhar o objeto. Para auxiliar esse processo, fora necessário a criação de um material impresso com canções sugeridas pelos alunos. Várias pesquisas foram feitas até descobrir um site que traria com maior facilidade cifras que pudessem ser transformar em notas alfabéticas para serem usadas nas tecnologias digitais móveis. Essa transformação foi realizada pela professora do LIE, pois nesse início de projeto os alunos necessitavam ter em mãos as partituras das músicas com as cifras transformadas em letras do teclado.

Após o período de apropriação, ficou fácil para os alunos tocarem várias canções no laptop, tablets e notebooks. Alguns até nem precisavam mais do auxílio do catálogo de cifras. Essa rápida apropriação e engajamento dos alunos no projeto gerou reconhecimento dos meios envolvidos. O reconhecimento do projeto surgiu na forma de convites. Convites esses que oportunizaram aos alunos apresentarem-se em vários eventos do município.

\subsection{Instrumentais de coleta de dados}

A observação e o registro permitem a inserção do investigador no ambiente da pesquisa. Nesse sentido, o acompanhamento das ações dos projetos foram realizadas por meio de entrevistas, depoimentos pessoais e das observações espontâneas e assistemáticas 
VII Congresso Brasileiro de Informática na Educação (CBIE 2018)

Anais do XXIV Workshop de Informática na Escola (WIE 2018)

realizadas por professores, alunos, gestores e pais de alunos, por meio das produções dos vídeos e campanhas realizadas pelos alunos. De acordo com o emprego da observação casual como método, foi possível realizá-la de maneira organizada por meio das anotações, impressões, registro fotográfico e conversas informais. A seguir, explanaremos, os detalhes sobre análise dos resultados e discussões do trabalho.

\section{Resultados e Discussão}

Nos dois projetos desenvolvidos, os alunos foram incentivados além do envolvimento da informática, o aprendizado de outras disciplinas, porém, de acordo com Moran (1995), eles podem ser incentivados a produzir dentro de uma determinada matéria no âmbito de um trabalho interdisciplinar. Do ponto de vista de aprendizagem no trabalho por projeto, Prado (2001) destaca a possibilidade de o aluno recontextualizar aquilo que aprendeu, bem como estabelecer relações significativas entre conhecimentos. Nesse processo, o aluno pode ressignificar os conceitos e as estratégias utilizadas na solução do problema de investigação que originou o projeto e, com isso, ampliar o seu universo de aprendizagem.

Neste sentido, ressaltamos que o projeto envolveu, além do estudo de mídias e tecnologias, o ensino de Português, Música, Literatura, Artes e História, favorecendo a apropriação tecnológica, inclusão digital e formação cidadã.

De acordo com os objetivos específicos traçados, dividimos a análise e discussão do resultado da pesquisa em dois tópicos, detalhando seu desenvolvimento quanto a: 1) resultados do projeto 1: Projeto Youtuber: Seja digital e não deixe ninguém para trás e o 2) resultados do projeto: Projeto Música e Tecnologia na escola.

\subsection{Resultado do projeto 1: Projeto Youtuber: Seja digital e não deixe ninguém para trás}

Compreendemos que a utilização das tecnologias de comunicação na sala de aula possibilita a inovação na prática de ensino e aprendizagem, ao permitir a circulação de informações de modo atraente e lúdico. Assim, recursos midiáticos, como o vídeo, possibilitaram o despertar da criatividade, à medida que estimularam a elaboração de aprendizados múltiplos, em consonância com a sensibilidade e emoções dos alunos, que tiveram a oportunidade de explorar diversos conteúdos e ambientes, observando o contexto histórico do qual fazem parte e constituíram narrativas, com suporte nas vivências e conhecimentos.

O uso do Youtube por meio do Concurso Aluno Digital proporcionou estímulo nos alunos, pois trouxe mobilização, motivação, criatividade, aprendizado e sensibilização, dentre outros aspectos, de modo que levou ao aluno e à população o conhecimento de um assunto importante por meio de um aprendizado prazeroso mediado pelas tecnologias. Neste sentido, Moran (1995) destaca que o vídeo promoveu uma ruptura nos processos educacionais pautados apenas nas linguagens verbal e escrita, trazendo para sala de aula o mundo externo, o cotidiano, as imagens, os sons de realidades próximas e distantes, a imaginação e a fantasia.

Durante o período de agosto de 2017, a Escola mobilizou a todos e obteve sucesso na $1^{\mathrm{a}}$ e $2^{\mathrm{a}}$ etapas do concurso. Na primeira etapa, dos seis finalistas quatro alunos da Escola foram vencedores e premiados com TVs e kits de conversores digitais, 
VII Congresso Brasileiro de Informática na Educação (CBIE 2018)

Anais do XXIV Workshop de Informática na Escola (WIE 2018)

conforme classificação. Na $2^{\mathrm{a}}$ etapa, que aconteceu por meio do voto popular on-line, dos três concorrentes de cada categoria, I e II, o primeiro lugar ficou com os alunos da Escola, recebendo como premiação um tablet com internet gratuita durante um ano. A Escola também foi premiada com uma TV de 40 polegadas, por ter sido uma das escolas que teve o maior número de vídeos inscritos, num total de sessenta e dois.

$\mathrm{Na}$ categoria I- Seja um Youtuber - os alunos do $2^{\circ}$ ano ao $4^{\circ}$ ano do Ensino Fundamental I estudaram sobre o assunto nas aulas de informática e em tablets e aparelhos celulares. Uns foram gravando os outros e, assim, criando seus tutoriais sobre o tema em questão, todos com o auxílio da professora de informática, que, após as gravações, editou e inseriu o cadastro dos alunos do site. Vale ressaltar que nessa categoria todos os premiados foram da Escola em estudo, valendo-se da dedicação, criatividade e entusiasmo de todos os envolvidos. Ser um Youtuber, ajudou o aluno a desenvolver habilidades de comunicação e a se portar em uma apresentação, uma vez que necessitou de ensaios sobre sua fala para a filmagem do vídeo.

Os vídeos criados pelos estudantes nessa categoria, tiveram os seguintes assuntos abordados: o que preciso fazer com minha TV antiga para receber o sinal digital; como fazer agendamento e retirar um kit se uma família participa de programas sociais do Governo Federal; como instalar um kit de conversão; como sintonizar os canais digitais etc.

$\mathrm{Na}$ categoria 2 - Eu sou um reporter - os alunos do $5^{\circ}$ ano do Ensino Fundamental I foram estimulados pela professora a produzirem seus vídeos com algum conhecido ou familiar, sobre o recebimento e implantação do kit conversor digital em sua residência e os resultados positivos da TV Digital. Os estudantes, por meio de aparelhos celulares, realizavam suas entrevistas com parentes e amigos e, após a gravação, entregavam os vídeos à professora, que editava e, posteriormente, na aula, compartilhava no YouTube.

Para auxiliar a gravação dos vídeos dos alunos do $5^{\circ}$ ano, a professora elaborou alguns questionamentos, como: a) Você possui TV de tubo? b) Você sabe quem tem direito de receber o kit conversor digital gratuito? c) Já instalou o seu? d) Qual a diferença da TV analógica para TV digital?

Nessa categoria, destacamos o interesse a autonomia do aluno em desenvolver os próprios vídeos, pois eles precisavam realizá-los sem a presença da professora, ultrapassando os limites da escola. A docente ficou apenas como mediadora no processo, sendo os alunos os sujeitos ativos. Dos três finalistas escolhidos, o primeiro lugar ficou com uma aluna da escola da presente pesquisa.

Para a gravação dos vídeos, foram tomadas algumas medidas de proteção da divulgação da imagem dos alunos, como a criação de um termo de autorização de imagem, que os responsáveis pelo aluno assinavam, para que os vídeos fossem publicados, conforme o artigo 79, do Decreto-Lei no 47 344, de 25-11-1966, (Código Civil Brasileiro).

O sucesso do trabalho desenvolvido teve grande repercussão dentro e fora da comunidade escolar. O conquista dos prêmios por meio do esforço dos alunos, emocionou professores e familiares. Segundo Papert (2008), o conhecimento torna-se valorizado, por ser útil, por ser possível compartilhar com outras pessoas e por 
VII Congresso Brasileiro de Informática na Educação (CBIE 2018)

Anais do XXIV Workshop de Informática na Escola (WIE 2018)

combinar com o estilo pessoal. O autor destaca ainda, que uma pequena escola criada em espírito atuante pode mobilizar a tecnologia como afirmação de identidade. $\mathrm{Na}$ figura 1, lê o depoimento de uma mãe, postado em uma rede social, cuja filha foi uma das vencedoras no concurso.

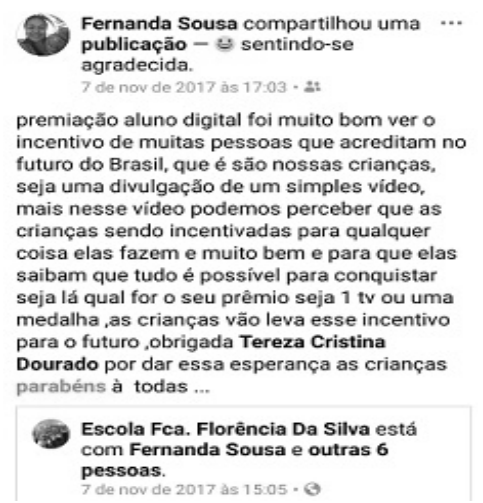

Figure 1. Depoimento de uma mãe em um rede social sobre o projeto

\subsection{Resultados do projeto 2: Projeto Música e Tecnologia na escola}

A linguagem musical atrelada ao uso da tecnologias móveis como laptops, tablets e notebooks possibilitou que os professores trabalhassem com seus alunos aspectos do currículo oculto e institucional da escola como o conhecimento, interação, envolvimento com o mundo, organização, respeito, dentre outros. A realização do projeto não proporcionou apenas uma experiência intelectual, ou cultural, mas completa-se, através do seu domínio, com possibilidades de transformar sujeitos, ampliando suas formas de perceber, interagir, agir e pensar.

Os resultados do projeto aconteceram de forma inesperada e intempestiva, através de convites para que os alunos participassem dos eventos educacionais e sociais promovidos pelo Município e outros orgãos. Durante os 3 anos de duração do projeto, os alunos realizaram mais de 40 apresentações que aconteceram em praças, universidades, teatros, supermercados, associações, secretarias, escolas e congressos, participaram de 2 reportagens em canais de Tvs e 2 concursos educacionais com a conquista do $1^{\circ}$ lugar, possibilitando um aprendizado repleto de descobertas e desafios.

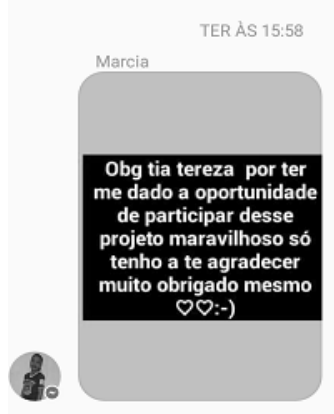

Figure 2. Depoimento de uma aluna em um rede social sobre o projeto

Os resultados coletados revelaram que não só os professores da escola, gestores e alunos (figura 2), mas toda a comunidade escolar reconheceu a importância da relação estabelecida entre música, criança, tecnologia e desenvolvimento com a realização do 
VII Congresso Brasileiro de Informática na Educação (CBIE 2018)

Anais do XXIV Workshop de Informática na Escola (WIE 2018)

projeto, pois foram apontadas experiências interativas que puderam enriquecer essa relação. A valorização do trabalho realizado também pode ser evidenciada através das postagens de pais de alunos, alunos, professores e toda comunidade nas redes sociais da escola, favorecendo a ampliação do mesmo e ressaltando a sua relevância, como mostraremos a seguir:

“[...] Os alunos ficam encantados querendo participar, não faltam as aulas e nem deixa de fazer atividades ligadas as demais disciplinas, pois os mesmos, sabem que, para fazer parte do projeto, precisam estar bem com o todo e isso levanta a auto estima de cada um [...]" (Depoimento da professor R postado no facebook no dia 12/06/2016)

O projeto ganhou proporções grandes e inexperadas conquistando na etapa estadual o Prêmios Professores do Brasil realizado pelo Ministério da Educação (MEC) em 2017, como um dos melhores projetos incritos. O Prêmio Professores do Brasil é uma iniciativa do Ministério da Educação juntamente com instituições parceiras que busca reconhecer, divulgar e premiar o trabalho professores de escolas públicas que contribuem para a melhoria dos processos de ensino e aprendizagem desenvolvidos nas salas de aula.

\section{Considerações finais}

Ante o exposto, comprovamos vários pontos positivos na utilização de projetos motivados por concursos educacionais, favorecendo a prática pedagógica do professor na sala de aula, auxiliando de maneira atraente, dinâmica e moderna, com muitas possibilidades.

Sobre o trabalho com projetos na escola Almeida (2000) defende que é uma forma de facilitar a atividade, a ação, a participação do aluno no seu processo de produzir fatos sociais, de trocar informações, de construir conhecimento. O trabalho com projeto objetiva ir além das limitações do currículo escolar, pois é uma forma mais organizada de possibilitar a aprendizagem discente.

Entende Papert (2008) que muitos professores têm dúvidas e medos, e compartilha com a maioria dos docentes que foram levados a experimentar o computador como instrumento de mudança. Sabemos que os avanços tecnológicos foram rápidos, porém os professores não podem se limitar a esse discurso e deixar de buscar meios para inovar e aprofundar-se nessa nova era.

Temos consciência de, que as participações nos concursos, partiu muito do interesse do professor em querer levar para suas aulas algo dinâmico, lúdico e criativo para seus alunos. De acordo com Veen e Wrakking (2009), os professores devem ficar atentos aos desafios do novo a todo instante, sendo esse novo não só conhecer as novas tecnologias, mas também dar espaço às novas atitudes educacionais, dentre elas, a atitude de confiar nos alunos no que tange ao fazer, ao querer e ao cumprir com liberdade. A professora da escola foi essencial para o sucesso do trabalho. Papert (2008) ressalta as ações pequenas de um professor podem semear progressos em uma turma.

Sabemos que atrair atenção e o interesse do aluno é uma tarefa bem difícil, pois o modelo tradicional de ensino, como o livro didático, não mais abarca o interesses dos alunos, numa sociedade onde as transformações ocorrem a todo momento. E a 
VII Congresso Brasileiro de Informática na Educação (CBIE 2018)

Anais do XXIV Workshop de Informática na Escola (WIE 2018)

utilização de projetos na educação vêm ganhando espaços e agregando valores cognitivos importantes para o desenvolvimento social.

Em decorrência do trabalho desenvolvido, a continuidade do estudo persistiu por meio dos próprios alunos, que continuaram desenvolvendo vídeos tutoriais e publicando em seus próprios canais, bem como tocando instrumentos musicais em locais como igrejas e aniversários. Essa ação, representa o desenvolvimento da autonomia dos alunos envolvidos nos projetos.

\section{Referências}

Almeida, F. J. \& Fonseca Júnior, F.M.(2000). Projetos e ambientes inovadores. Brasília: Secretaria de Educação a Distância - SEED/ Proinfo - Ministério da Educação.

Almeida, M.E.B. de. (2002). Como se trabalha com projetos (Entrevista). Revista TV ESCOLA. Secretaria de Educação a Distância. Brasília: Ministério da Educação, SEED, $n^{\circ}$ 22, março/abril.

Acampora, Bianca. (2014). Guia Prático para professores de Educação Infantil.: http://www.revistaguiafundamental.com.br. Ano 10 - Edição 136 - Novembro.

Brasil. Código Civil (2002). Código civil brasileiro e legislação correlate. - 2.ed. Brasília: Senado Federal, Subsecretaria de Edições Técnicas, 2008.

Burgess, Jean. Green, Joshua. (2009). YouTube e a Revolução Digital: como o maior fenômeno da cultura participativa transformou a mídia e a sociedade. Tradução de Ricardo Giassetti. São Paulo: Aleph.

Caetano, S. V. N.; Falkembach, G. A. M.(2013). YouTube: uma opção para uso do vídeo na EAD. Porto Alegre: UFRGS.

Gabriel, M. (2013). Educar: a revolução digital na educação. São Paulo: Saraiva.

Moran, J. M. (1995). O vídeo na sala de aula. São Paulo. Disponível em: $<$ http://www.eca.usp.br/prof/moran/ vidsal.htm>. Acesso em: 20 de maio de 2013.

Papert, Seymour. (2008). A máquina das crianças: repensando a escola na era da informática/ Seymour Papert; tradução Sandra Costa. - ed. Rev.-Porto Alegre: Artmed, 2008.

Prado, M.E.B.B. (2001). Articulando saberes e transformando a prática. Boletim do Salto para o Futuro. Série Tecnologia e Currículo, TV ESCOLA. Brasília: Secretaria de Educação a Distância - SEED. Ministério da Educação.

Ruiz, J. A. (2010). Metodologia científica: guia para eficiência nos estudos. 6 ed. São Paulo: Atlas. $180 \mathrm{p}$.

Veen, W.; vrakking, B. (2009). Homo Sapiens: educando na era digital. Porto Alegre: Artmed.

Willoughby, Nick.(2017). Criando vídeos para o YouTube. Rio de Janeiro: Alta Books.

Yin, Robert K. (2001). Estudo de Caso: planejamento e métodos. 2.ed.Porto Alegre: Bookman. 